九州大学学術情報リポジトリ

Kyushu University Institutional Repository

\title{
Karyotype Analysis of Korean Lilium maximowiczii Regal Populations
}

Trong, Nguyen Xuan

Oriental Bio-herb Research Institute, Kangwon National University | Institute of Agro-Biology, Vietnam National University of Agriculture

Kim, Ji Young

Department of Horticulture, Kangwon National University

Rai, Rameshwar

Department of Horticulture, Kangwon National University

Kim, Jong Hwa

Oriental Bio-herb Research Institute, Kangwon National University | Department of Horticulture, Kangwon National University

他

https://doi.org/10.5109/1526344

出版情報: 九州大学大学院農学研究院紀要. 60 (2)，pp.315-322，2015-09-18. Faculty of Agriculture, Kyushu University

バージョン：

権利関係 : 


\title{
Karyotype Analysis of Korean Lilium maximowiczii Regal Populations
}

\author{
Nguyen Xuan TRUONG ${ }^{1,2}$, Ji Young KIM ${ }^{3}$, Rameshwar RAI ${ }^{3}$, Jong Hwa KIM ${ }^{1,3 *}$, \\ Nam Soo KIM ${ }^{4 * *}$ and Akira WAKANA
}

\author{
Laboratory of Horticultural Science, Department of Bioresource Science, Faculty of Agriculture, \\ Kyushu University, Fukuoka 812-8581, Japan \\ (Received May 8, 2015 and accepted May 19, 2015)
}

\begin{abstract}
Detailed karyotypes analyses were carried out in 30 populations of Korean L. maximowiczii Regel. The populations were constituted with 43 diploids $(2 n=2 x=24)$ and 38 triploids $(2 n=3 x=36)$. The lengths of mitotic metaphase chromosomes ranged from $13.22 \mu \mathrm{m}$ to $25.18 \mu \mathrm{m}$, with a total length of $203.78 \mu \mathrm{m}$ in diploid plants. In triploid plants, the chromosome lengths ranged from $14.28 \mu \mathrm{m}$ to $27.75 \mu \mathrm{m}$, with a total length of $214.42 \mu \mathrm{m}$. There was only one cytotype identified by karyotype analysis in both diploid and triploid populations. The basic set of somatic chromosome complement consists of two metacentrics (chromosomes a and b), two subtelocentrics (chromosomes $\mathbf{c}$ and $\mathbf{d}$ ), and eight telocentrics (chromosomes e, f, g, h, i, j, k, and $\mathbf{l}$ ) in both diploid and triploid populations. Four loci of 45S rRNA genes were observed by FISH, and three of the four loci correspond to the secondary constrictions. One additional 45S rRNA locus was observed by FISH at the near telomere of the long arm of a set of telocentric chromosomes. There were two 5S rRNA gene loci, which were closely placed on the long arm of a set of subtelocentric chromosomes that were not the 45S rRNA loci-carrying chromosomes. In conclusion, the karyotypes in both diploid and triploid populations were identical, implying that the triploid organisms are autotriploids.
\end{abstract}

Key words: autotriploid, chromosomal landmarks, FISH, Maximowicz's lily

\section{INTRODUCTION}

Twelve lily species, mainly belonging to the sections Sinomartagon, Martagon, and Leucolirion, are native to Korea (Kim, 1996). Lilium species found in Korea include all three types of the leaf arrangement (with single whorls, multiple whorls, and scattered leaves) within the genus (Lighty, 1968). L. maximowiczii, which is believed to be the most closely related to the origin of triploid L. lancifolium based on morphological and cytological characteristics (Noda, 1966 and 1974), is widely distributed in Eastern Asia, including Japan, Korea, Manchuria, northern China, and Ussuri in Russia (Asano, 1986; Baranova, 1969).

Wilson (1925) reported a wide distribution of $L$. maximowiczii around the mountain plateau of Hamkyungnam-do Province in North Korea. Lighty (1968) explored Lilium populations in South Korea and reported a limited geographical distribution of $L$. maximowiczii only in Gangwon-do Province. L. maximowiczii and L. leichtlinii var. leichtlinii are the most common lilies in Japan and are widely distributed throughout the Japanese archipelago from the seashore to the mountains over 2,000 meters in elevation (Shimizu, 1969). Jeong (1991) and other researchers collected specimens

Oriental Bio-herb Research Institute, Kangwon National University, Chuncheon 200-701, Korea

Institute of Agro-Biology, Vietnam National University of Agriculture, Hanoi, Vietnam

Department of Horticulture, Kangwon National University, Chuncheon 200-701, Korea

${ }^{4}$ Department of Molecular Biosciences, Kangwon National University, Chuncheon 200-701, Korea

* Corresponding author (E-mail: jonghwa@kangwon.ac.kr)

** Co-corresponding author (E-mail: kimnamsu@kangwon.ac. $\mathrm{kr}$ ) sporadically from Keumo-do Island, the southernmost part of Korea, to Gangwon-do Province, the northernmost part of South Korea; however, some specimens are suspected to have been misidentified, and their identities are uncertain (KBIS, 2013; Kim et al., 2015). We extensively examined the reported sites of the specimens in the southern part of Korea, but were unable to find L. maximowiczii plants in many places now. L. maximowiczii and L. leichtlinii var. leichtlinii have been thought to comprise only diploid $(2 n=2 x=24)$ plants in Japan (Morinaga and Fukushima, 1931; Kumazawa and Kimura, 1947; Kurita, 1948; Stewart, 1947; Noda, 1956, 1966, 1974, and 1977; Ogihara, 1960; Song and Seo, 1988) and Korea (Son, 1982; Song, 1987; Jeong, 1991; Sultana et al., 1010). However, detailed ploidy analyses have not been attempted on these specimens.

Recently, we found that L. maximowiczii plants grow in very scattered populations and are distributed in steep mountain ranges in Chungcheongbuk-do, Gyeonggi-do, and Gangwon-do Provinces, Korea. Their habitats do not overlap with those of diploid L. lancifolium in South Korea (Kim et al., 2015). Furthermore, we found that triploid plants are far more common than diploid plants in our analysis of Korean L. maximowiczii populations, and that triploid and diploid populations have only one cytotype from the conventional chromosome analysis (Kim et al., 2015). These results made it clear that Korean L. maximowiczii includes both diploid and triploid forms in the Lilium genus.

On the other hand, Noda (1977) reported A and B cytotypes of karyotypes in the Japanese L. maximowiczii collections. While the arm index and general chromosome morphology were similar between two cytotypes, chromosomes in the A cytotypes were larger than those of the B cytotypes. He also reported the presence 
of different numbers of B-chromosomes in the Japanese accessions. It is interesting that while Japanese accessions have numerous B-chromosomes, none of the Korean accessions have B-chromosomes, which requires further analysis of detailed karyotype variations in Korean L. maximowiczii. Conventional staining methods have some limitations in unequivocal identification of individual chromosomes of similar size and morphology in Lilium species (Song, 1987). Fluorescence in situ hybridization (FISH), using ribosomal DNAs as probes, provides information of nucleolar organizing regions (NORs) (Heslop-Harison et al., 1991) and has been used to analyze chromosomes in several Lilium species (Lim et al., 2001; Marasek et al., 2004; Hwang et al., 2011).

The purpose of this study is to understand detailed karyotype variations in diploid and triploid populations of Korean L. maximowiczii, using chromosomal landmarks such as chromosome length, arm ratio, secondary constrictions, DAPI bands, and FISH signals using $45 \mathrm{~S}$ rRNA and 5S rRNA genes.

\section{MATERIAL AND METHODS}

\section{Materials}

Forty-three diploid bulbs were collected from fourteen populations, and thirty-eight triploid bulbs were collected from sixteen populations (Table 1). These accessions were planted in pots containing a mixture of perlite and peat moss (1:3) and cultivated at the university farm of Kangwon National University, South Korea. The active root tips were harvested in the early morning,

Table 1. Locality and number of plants analyzed from each native Korean L. maximowiczii population

\begin{tabular}{|c|c|c|c|c|}
\hline $\begin{array}{l}\text { Population } \\
\text { number }\end{array}$ & Locality & Ploidy & $\begin{array}{l}\text { No. of plants } \\
\text { analyzed }^{2}\end{array}$ & $\begin{array}{l}\text { Accession } \\
\text { number }\end{array}$ \\
\hline 1 & Daegi-ri, Wangsan-myeon, Gangneung-si, GW & $2 \mathrm{x}$ & 10 & GWL1458 \\
\hline 2 & Yongsan-ri,Daegwanryeong-myeon, Pyeongchang-gun, GW & $2 \mathrm{x}$ & 5 & GWL1451 \\
\hline 3 & Songgye-ri, Sillim-myeon, Wonju, GW & $2 \mathrm{x}$ & 2 & GWL1484 \\
\hline 4 & Hoenggye-ri,Daegwanryeong-myeon,Pyeongchang-gun,GW & $2 \mathrm{x}$ & 4 & GWL1302 \\
\hline 5 & Mahyeon-ri, Sangseo-myeon, Hwacheon-gun, GW & $2 \mathrm{x}$ & 2 & GWL1473 \\
\hline 6 & Woechon-ri, Cheolwon-ub, cheolwon-gun, GW & $2 \mathrm{x}$ & 2 & GWL1485 \\
\hline 7 & Samhwa-ri, Hanam-myun, Hwacheon-gun, GW & $2 \mathrm{x}$ & 2 & GWL1459 \\
\hline 8 & Mahyeon-ri, Keunnam-myun, cheolwon-gun, GW & $2 \mathrm{x}$ & 2 & GWL1481 \\
\hline 9 & Sanyang-ri, Sangseo, Hwacheon-gun, GW & $2 \mathrm{x}$ & 2 & GWL1486 \\
\hline 10 & Sanyang-ri, Sangseo-myeon, Hwacheon-gun, GW & $2 \mathrm{x}$ & 2 & GWL1487 \\
\hline 11 & Sanyang-ri, Sangseo-myeon, Hwacheon-gun, GW & $2 \mathrm{x}$ & 3 & GWL1488 \\
\hline 12 & Sanyang-ri, Sangseo-myeon, Hwacheon-gun, GW & $2 \mathrm{x}$ & 2 & GWL1489 \\
\hline 13 & Eron-ri, SeoSeok-myun, Hongcheon-gun, GW & $3 \mathrm{x}$ & 2 & GWL1457 \\
\hline 14 & Mandae-ri, Haean-myeon, Yanggu-gun, GW & $3 \mathrm{x}$ & 2 & GWL1300 \\
\hline 15 & Bangdong-ri, Kirin-myun,Inje-gun, GW & $3 x$ & 2 & GWL1469 \\
\hline 16 & Bangdong-ri, Kirin-myun, Inje-gun, GW & $3 x$ & 2 & GWL1490 \\
\hline 17 & Mahyeon-ri, Keunnam-myun, cheolwon-gun, GW & $3 \mathrm{x}$ & 2 & GWL1491 \\
\hline 18 & Mahyeon-ri, Sangseo-myeon, Hwacheon-gun, GW & $3 \mathrm{x}$ & 2 & GWL1477 \\
\hline 19 & Eoron-ri, Nam-myeon, Inje-gun, GW & $3 \mathrm{x}$ & 2 & GWL1466 \\
\hline 20 & Tosung-ri, Galmal-eup, Cheolwon-gun, GW & $3 \mathrm{x}$ & 2 & GWL1492 \\
\hline 21 & Sagok-ri, Geunnam-myeon, Cheolwon-gun, GW & $3 \mathrm{x}$ & 3 & GWL1493 \\
\hline 22 & Yookdan-ri, Keunnam-myun, Cheolwon-gun, GW & $3 \mathrm{x}$ & 2 & GWL1494 \\
\hline 23 & Buchon-ri, Sangseo-myeon, Hwacheon-gun, GW & $3 \mathrm{x}$ & 2 & GWL0115 \\
\hline 24 & Samhwa-ri, Hanam-myeon, Hwacheon-gun, GW & $3 \mathrm{x}$ & 5 & GWL1460 \\
\hline 25 & Suib-Ri, Seojong-myeon, Yangpyeong-gun, GG & $3 x$ & 2 & GWL1253 \\
\hline 26 & Song-am-ri, Sabuk-myeon, Chuncheon-si, GW & $3 \mathrm{x}$ & 2 & GWL1425 \\
\hline 27 & Saeun-ri, chilsung-myun, Goesan-gun, CB & $3 \mathrm{x}$ & 3 & GWL1118 \\
\hline 28 & Cheondong-ri,Danyangub, Danyang-gun, CB & $2 \mathrm{x}$ & 6 & GWL1495 \\
\hline 29 & Cheondong-ri,Danyangub, Danyang-gun, CB & $3 \mathrm{x}$ & 3 & GWL1496 \\
\hline 30 & Cheondong-ri,Danyangub, Danyang-gun, CB & $2 \mathrm{x}$ & 7 & GWL1497 \\
\hline
\end{tabular}

$2 x=43$ plants in 13 sites, $3 x=38$ plants in 15 sites

${ }^{y}$ GWL serial number is the accession number of registration to RDA Gene bank Korea

Abbreviation: GWL, Gangwon-do lily germplasm; GW, Gangwon-do; GG, Gyeonggi-do; CB, Chungchungbuk-do 
and pretreated in $0.2 \%$ colchicine solution at $4^{\circ} \mathrm{C}$ for $24 \mathrm{~h}$. The materials were rinsed three times with tap water, then fixed in acetic acid : ethanol (1:3) for $24 \mathrm{~h}$ at room temperature. The root tips were then rinsed three times with tap water and stored in $70 \%$ ethanol at $-20^{\circ} \mathrm{C}$.

\section{Karyotype analysis}

The stored root tips were rinsed thoroughly with water before softening in $1 \mathrm{~N} \mathrm{HCl}$ at $60^{\circ} \mathrm{C}$ for $5 \mathrm{~min}$. Chromosomes of root tip cells at metaphase were stained in $1 \%(\mathrm{w} / \mathrm{v})$ aceto-carmine and prepared using a squash technique described by Fernandez et al. (1998) with some minor modifications. Five well-spread sets of metaphase chromosomes from each accession were photographed. The karyotype analysis was carried out according to the method developed by Noda (1977). The total chromosome length, the length of long arm and short arm, the arm ratio index (ratio of long arm length to short arm length), and the centromeric index (percentage of short arm length to the total length of chromosome) were measured using Micro Measure 3.3 software (Reeves and Tear, 2000). Nomenclature for the centromeric position on chromosome was classified according to the arm index (1.0-1.7: metacentric; 1.7-3.0: submetacentric; 3.0-7.0: subtelocentric; $\geq 7.0$ : telocentric) (Levan et al., 1964).

\section{Slide preparation for fluorescence in situ hybridi- zation (FISH)}

The stored root tips were rinsed several times with water, then cut to about $1 \mathrm{~mm}$ in length and put into $1.5 \mathrm{ml}$ tubes with enzyme solution $(\mathrm{pH} 4.5)$ containing $0.3 \%(\mathrm{w} / \mathrm{v})$ cellulase $\mathrm{RS}, 0.2 \%(\mathrm{w} / \mathrm{v})$ pectolyase $\mathrm{Y} 23$, $0.2 \%(\mathrm{w} / \mathrm{v})$ macerozyme $\mathrm{R} 10,0.07 \mathrm{M} \mathrm{KCl}$, and $1 \mathrm{mM}$ methylene diamine tetra-acetic acid (EDTA), then incubated at $37^{\circ} \mathrm{C}$ for $10 \mathrm{~min}$. The root tips were then gently rinsed in distilled water. One softened root tip was placed on each slide, immediately mixed with $10 \mu \mathrm{l} 1 \%$ acetocarmine using a needle, covered with a cover glass $(20 \times$ $20 \mathrm{~mm}$ ), and squashed with thumb. The positions of the well-spread chromosomes were marked under the microscope. The slide was placed in liquid nitrogen, and after the cover glass was removed using a razor blade, it was quickly transferred to absolute ethanol for $5 \mathrm{~min}$, airdried, and stored again at $-20^{\circ} \mathrm{C}$ until use.

\section{Probes for FISH}

The 5S rDNA and 45S rDNA probes were directly labeled with fluorescein-12-dUTP and tetramethylrhodamine-5-dUTP, respectively (Duchefa, Enzo Life science, USA). Nick translation was performed according to the manufacturer's instructions (Roche, Germany). To remove unbound nucleotide and enhance probe concentration, the protocol described by Karafiátová et al. (2013) was followed with some modifications. The labeled probe product was transferred into a $1.5 \mathrm{ml}$ tube; precipitated by adding $3 \mathrm{M}$ sodium acetate (NaAc; $\mathrm{pH}$ 5.2), cool absolute ethanol, and $100 \mu \mathrm{g}$ salmon sperm DNA (Sigma-Aldrich, Germany); then incubated at $-20^{\circ} \mathrm{C}$ overnight. The probes were centrifuged at $4^{\circ} \mathrm{C}$ at $14,000 \times \mathrm{g}$ for $15 \mathrm{~min}$. The supernatant was discarded, and $200 \mu \mathrm{l} 70 \%$ ethanol was added before centrifuging the probes again. The supernatant was again discarded, and the probes were air-dried in the dark. The probes were dissolved in hybridization buffer containing 50\% deionized formamide (v/v), 10\% dextran sulfate (w/v), $0.5 \%$ sodium dodecyl sulfate, and $2 \mathrm{X}$ saline-sodium citrate buffer (SSC). The probe quality was confirmed on a $1 \%$ agarose gel, and the probes were stored at $-20^{\circ} \mathrm{C}$.

\section{Fluorescence in situ hybridization and microscopy}

The in situ hybridization procedure (Zhang et al., 2014) consisted of four steps. 1) Pretreatment of chromosomes: the slide was treated with $100 \mu \mathrm{g} \mathrm{mL} \mathrm{mNase}^{-1}$ in 2X SSC for one hour at $37^{\circ} \mathrm{C}$ then stabilized in $4 \%$ paraformaldehyde for $10 \mathrm{~min}$ at room temperature. After each treatment, the slide was washed with $2 \mathrm{X}$ SSC three times for 5 min each. The slide was then dehydrated in a series of $70 \%, 95 \%$, and $100 \%$ ethanol for 5 min each and air-dried at room remperature. 2) Denaturation of chromosomes: the slide was treated with $70 \%$ formamide in $2 \mathrm{X} \mathrm{SSC}$ at $70^{\circ} \mathrm{C}$ for $2 \mathrm{~min}$, quickly dehydrated in a series of $70 \%, 95 \%$, and $100 \%$ ethanol at $-15^{\circ} \mathrm{C}$ for $5 \mathrm{~min}$ each, and air-dried at room temperature. 3) Hybridization: hybridization buffer containing the probe and block DNA was denatured at $75^{\circ} \mathrm{C}$ for $10 \mathrm{~min}$, quickly put on ice for $10 \mathrm{~min}$, and briefly spun down. This mix was added $(30 \mu \mathrm{l})$ to each slide, and the slide was covered with a cover glass $(20 \times 40 \mathrm{~mm})$. The DNA was denatured at $80^{\circ} \mathrm{C}$ for 5 min then incubated at $37^{\circ} \mathrm{C}$ overnight in a humid box. 4) Post-hybridization and detection: The cover glass was removed, and the slide was washed with $2 \mathrm{X}$ SSC two times at $42^{\circ} \mathrm{C}$ for 5 min each, with $50 \%$ formamide for $10 \mathrm{~min}$ at $42^{\circ} \mathrm{C}$, and again with 2X SSC two times at $42^{\circ} \mathrm{C}$ and one time at room temperature for $5 \mathrm{~min}$. The slide was then dehydrated in a series of $70 \%, 95 \%$, and $100 \%$ ethanol at room temperature for $5 \mathrm{~min}$ each and air-dried at room temperature in the dark. The chromosomes were counterstained with $30 \mu \mathrm{l}$ 4',6'-diamidino-2-phenylindole (DAPI) in Vectashield (Vector Laboratories, Inc., USA), examined using a fluorescent microscope (Nikon Eclipse 80i, Japan), and captured using a Nikon digital camera (D90, Japan). Images were edited in Adobe Photoshop CS4 to facilitate the analysis of individual chromosomes.

\section{RESULTS}

\section{Somatic chromosomes of $L$. maximowiczii}

The diploid plants have the somatic chromosome numbers of $2 n=2 x=24$ (Fig. 1). We did not detect aneuploidy or B-chromosomes. Chromosome length at metaphase ranged from $13.22 \mu \mathrm{m}$ to $25.18 \mu \mathrm{m}$, and the total chromosome length of the haploid complement was $203.78 \mu \mathrm{m}$. The 12 somatic chromosomes included two metacentric (chromosome a and b), two subtelocentric (chromosome $\mathbf{c}$ and $\mathbf{d}$ ), and eight telocentric chromosomes (chromosome $\mathbf{e}, \mathbf{f}, \mathbf{g}, \mathbf{h}, \mathbf{i}, \mathbf{j}, \mathbf{k}$, and l) (Table 2). The chromosomes were designated according to the system established by Noda (1977).

The triploid plants have the somatic chromosome 

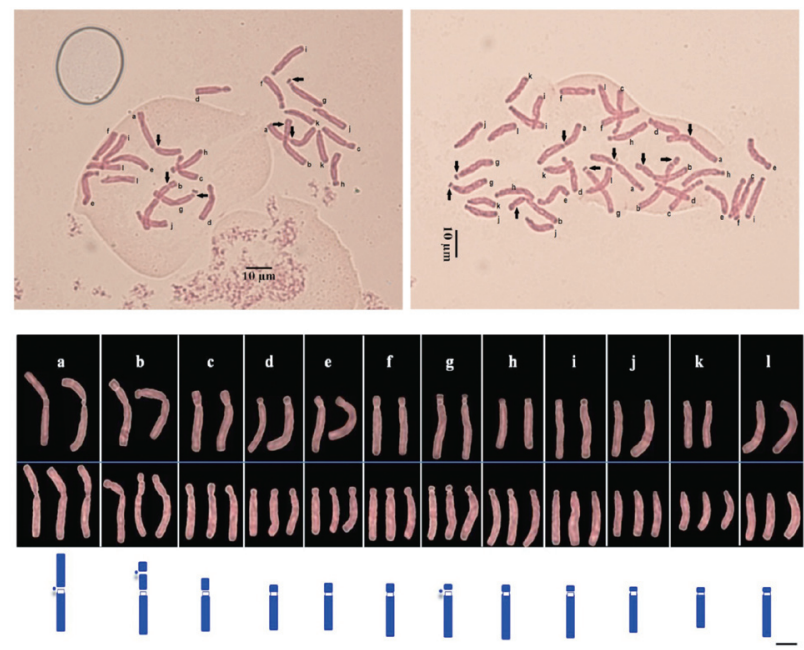

Fig. 1. Mitotic metaphase chromosomes and karyotypes of diploid and triploid $L$. maximowiczii using aceto-carmine stain. Idiogram shows the secondary constructions on the chromosomes of $L$. maximowiczii. Arrows indicate secondary constrictions. The bars represent a length of $10 \mu \mathrm{m}$.

numbers of $2 n=3 x=36$ (Fig. 1 ). We did not detect aneuploidy or B-chromosomes in the triploid accessions. Chromosomes of the triploids were measured slightly longer than those of diploid with a range from $14.28 \mu \mathrm{m}$ to $27.75 \mu \mathrm{m}$. There were three sets of two metacentric chromosomes (a and b), three sets of two subtelocentric chromosomes (c and $\mathbf{d}$ ), and three sets of eight telocentric chromosomes (e, f, $\mathbf{g}, \mathbf{h}, \mathbf{i}, \mathbf{j}, \mathbf{k}$, and $\mathbf{l}$ ) (Table 3). The total chromosome length of the monoploid complement was $214.42 \mu \mathrm{m}$.

\section{Chromosome identification}

Individual chromosomes in both diploid and triploid plants were distinguished by chromosome length, chromosome index (arm ratio), secondary constrictions, DAPI bands, and rRNA loci by conventional aceto-carmine, DAPI staining and FISH (Fig. 2 and 3, Tables 2 and 3). Three sets of chromosomes exhibited constant secondary constrictions proximal to the centromere in the short arm (chromosome $\mathbf{a}$ and $\mathbf{g}$ ) and near the telomere in the short arm (chromosome b). There were five sets of chromosomes showing DAPI bands, which are believed to be constitutive heterochromatic regions. The DAPI bands were at the interstitial regions in short arms of metacentric chromosomes and the middle of long arms of one subtelocentric chromosome and two telocentric chromosomes. Four loci for 45S rRNA genes were observed. Three of the 45S rRNA loci detected by FISH corresponded to the secondary constrictions. One additional 45S rRNA locus was observed by FISH at the proximal telomere of the long arm of a set of telocentric chromosomes on chromosome f (Table 2 and 3, Fig. 2 and 3). Two 5S rRNA gene loci were observed on the long arm of a set of subtelocentric chromosomes (chromosome c) that do not possess 45S rRNA loci.

The chromosomes were identified based on the following chromosome landmarks, indices, and lengths. Chromosome $\mathbf{a}$ is metacentric and the longest chromosome. It also contains a $45 \mathrm{~S}$ rRNA locus on the minor secondary constriction near the centromere of the short arm and a DAPI band in the interstitial site of the short arm. Chromosome $\mathbf{b}$ is metacentric and the second-longest chromosome. It possesses a $45 \mathrm{~S}$ rRNA locus at a large secondary constriction near the telomere of the short arm and a DAPI band at the interstitial site in short arm. Chromosome $\mathbf{c}$ is a subtelocentric chromosome containing two $5 \mathrm{~S}$ rRNA loci near the telomere of the long arm. Chromosome $\mathbf{d}$ is a subtelocentric chromosome that includes a DAPI band proximal to the centromere in the long arm. Chromosome $\mathbf{e}$ is the longest chromosome among telocentric chromosome that includes a DAPI band proximal to the centromere in the long arm. Chromosome

Table 2. Karyotype summary of natural diploids of Korean L. maximowiczii populations

\begin{tabular}{|c|c|c|c|c|c|c|c|c|}
\hline \multirow{2}{*}{$\begin{array}{c}\text { Chromo- } \\
\text { some } \\
\text { number }\end{array}$} & \multirow{2}{*}{$\begin{array}{l}\text { Length each } \\
\quad(\mu \mathrm{m})\end{array}$} & \multirow{2}{*}{$\begin{array}{l}\text { Long arm } \\
\text { length }(\mu \mathrm{m})\end{array}$} & \multirow{2}{*}{$\begin{array}{c}\text { Short arm } \\
\text { length }(\mu \mathrm{m})\end{array}$} & \multirow{2}{*}{$\begin{array}{c}\text { Arm } \\
\text { Ratio (L/S) }\end{array}$} & \multirow{2}{*}{$\begin{array}{l}\text { Chromosome } \\
\text { type }\end{array}$} & \multicolumn{2}{|c|}{ Location of rDNA gene } & \multirow{2}{*}{$\begin{array}{l}\text { DAPI } \\
\text { band }\end{array}$} \\
\hline & & & & & & $5 \mathrm{~S}$ & $45 \mathrm{~S}$ & \\
\hline $\mathbf{a}$ & $25.18 \pm 0.45$ & $14.63 \pm 0.30$ & $10.55 \pm 0.25$ & $1.39 \pm 0.03$ & metacentric & - & $\mathrm{S}$ & S \\
\hline $\mathbf{b}$ & $22.54 \pm 0.34$ & $13.74 \pm 0.20$ & $8.81 \pm 0.17$ & $1.56 \pm 0.02$ & metacentric & - & $\mathrm{S}$ & $\mathrm{S}$ \\
\hline c & $14.85 \pm 0.27$ & $11.58 \pm 0.23$ & $3.28 \pm 0.08$ & $3.53 \pm 0.13$ & subtelocentric & $\mathrm{L}$ & - & - \\
\hline d & $14.79 \pm 0.35$ & $12.77 \pm 0.35$ & $2.02 \pm 0.05$ & $6.32 \pm 0.28$ & subtelocentric & - & - & $\mathrm{L}$ \\
\hline $\mathbf{e}$ & $17.74 \pm 0.36$ & $15.76 \pm 0.38$ & $1.98 \pm 0.08$ & $7.91 \pm 0.37$ & telocentric & - & - & $\mathrm{L}$ \\
\hline $\mathbf{f}$ & $16.06 \pm 0.33$ & $14.25 \pm 0.34$ & $1.80 \pm 0.09$ & $7.96 \pm 0.68$ & telocentric & - & $\mathrm{L}$ & - \\
\hline $\mathbf{g}$ & $17.51 \pm 0.30$ & $15.95 \pm 0.29$ & $1.56 \pm 0.05$ & $10.22 \pm 0.54$ & telocentric & - & $\mathrm{S}$ & - \\
\hline $\mathbf{h}$ & $16.81 \pm 0.35$ & $15.37 \pm 0.34$ & $1.44 \pm 0.05$ & $10.66 \pm 0.79$ & telocentric & - & - & - \\
\hline $\mathbf{i}$ & $16.38 \pm 0.29$ & $15.12 \pm 0.27$ & $1.26 \pm 0.03$ & $12.01 \pm 0.48$ & telocentric & - & - & $\mathrm{L}$ \\
\hline $\mathbf{j}$ & $14.61 \pm 0.25$ & $13.63 \pm 0.24$ & $0.98 \pm 0.06$ & $13.95 \pm 0.17$ & telocentric & - & - & - \\
\hline $\mathbf{k}$ & $13.22 \pm 0.30$ & $12.37 \pm 0.30$ & $0.85 \pm 0.02$ & $14.55 \pm 0.64$ & telocentric & - & - & - \\
\hline 1 & $14.09 \pm 0.40$ & $13.47 \pm 0.40$ & $0.62 \pm 0.02$ & $21.70 \pm 1.26$ & telocentric & - & - & - \\
\hline Total & 203.78 & 168.63 & 35.15 & & & & & \\
\hline
\end{tabular}

${ }^{2}$ Mean \pm standard error, $n=100$; S: short arm; L: long arm 
Table 3. Karyotype summary of natural triploids of Korean L. maximowiczii populations

\begin{tabular}{|c|c|c|c|c|c|c|c|c|}
\hline \multirow{2}{*}{$\begin{array}{l}\text { Chromo- } \\
\text { some } \\
\text { number }\end{array}$} & \multirow{2}{*}{$\begin{array}{l}\text { Length each } \\
\qquad(\mu \mathrm{m})\end{array}$} & \multirow{2}{*}{$\begin{array}{l}\text { Long arm } \\
\text { length }(\mu \mathrm{m})\end{array}$} & \multirow{2}{*}{$\begin{array}{c}\text { Short arm } \\
\text { length }(\mu \mathrm{m})\end{array}$} & \multirow{2}{*}{$\begin{array}{c}\text { Arm } \\
\text { Ratio }(\mathrm{L} / \mathrm{S})\end{array}$} & \multirow{2}{*}{$\begin{array}{c}\text { Chromosome } \\
\text { type }\end{array}$} & \multicolumn{2}{|c|}{ Location of rDNA gene } & \multirow{2}{*}{$\begin{array}{l}\text { DAPI } \\
\text { band }\end{array}$} \\
\hline & & & & & & $5 \mathrm{~S}$ & $45 \mathrm{~S}$ & \\
\hline $\mathbf{a}$ & $27.75 \pm 0.23$ & $16.09 \pm 0.16$ & $11.65 \pm 0.11$ & $1.38 \pm 0.02$ & metacentric & - & S & S \\
\hline $\mathbf{b}$ & $22.89 \pm 0.22$ & $15.35 \pm 0.19$ & $7.54 \pm 0.11$ & $2.03 \pm 0.04$ & metacentric & - & S & S \\
\hline c & $18.03 \pm 0.21$ & $15.76 \pm 0.21$ & $2.27 \pm 0.07$ & $6.95 \pm 0.17$ & subtelocentric & $\mathrm{L}$ & - & - \\
\hline d & $17.63 \pm 0.23$ & $15.90 \pm 0.23$ & $1.73 \pm 0.04$ & $9.18 \pm 0.17$ & subtelocentric & - & - & $\mathrm{L}$ \\
\hline $\mathbf{e}$ & $19.07 \pm 0.21$ & $17.60 \pm 0.22$ & $1.47 \pm 0.04$ & $11.97 \pm 0.23$ & telocentric & - & - & $\mathrm{L}$ \\
\hline $\mathbf{f}$ & $15.78 \pm 0.24$ & $14.63 \pm 0.24$ & $1.15 \pm 0.04$ & $12.74 \pm 0.25$ & telocentric & - & $\mathrm{L}$ & - \\
\hline $\mathbf{g}$ & $15.47 \pm 0.23$ & $14.42 \pm 0.23$ & $1.05 \pm 0.04$ & $13.68 \pm 0.31$ & telocentric & - & $\mathrm{S}$ & - \\
\hline $\mathbf{h}$ & $15.59 \pm 0.20$ & $14.60 \pm 0.19$ & $0.99 \pm 0.03$ & $14.69 \pm 0.38$ & telocentric & - & - & - \\
\hline $\mathbf{i}$ & $15.23 \pm 0.22$ & $14.31 \pm 0.22$ & $0.92 \pm 0.03$ & $15.49 \pm 0.40$ & telocentric & - & - & $\mathrm{L}$ \\
\hline $\mathbf{j}$ & $15.32 \pm 0.19$ & $14.53 \pm 0.19$ & $0.79 \pm 0.03$ & $18.44 \pm 0.42$ & telocentric & - & - & - \\
\hline $\mathbf{k}$ & $14.97 \pm 0.16$ & $14.28 \pm 0.17$ & $0.69 \pm 0.03$ & $20.70 \pm 0.43$ & telocentric & - & - & - \\
\hline 1 & $16.69 \pm 0.26$ & $16.14 \pm 0.26$ & $0.55 \pm 0.02$ & $29.35 \pm 0.80$ & telocentric & - & - & - \\
\hline Total & 214.42 & 183.60 & 30.81 & & & & & \\
\hline
\end{tabular}

${ }^{2}$ Mean \pm standard error, $\mathrm{n}=150$; S: short arm; L: long arm
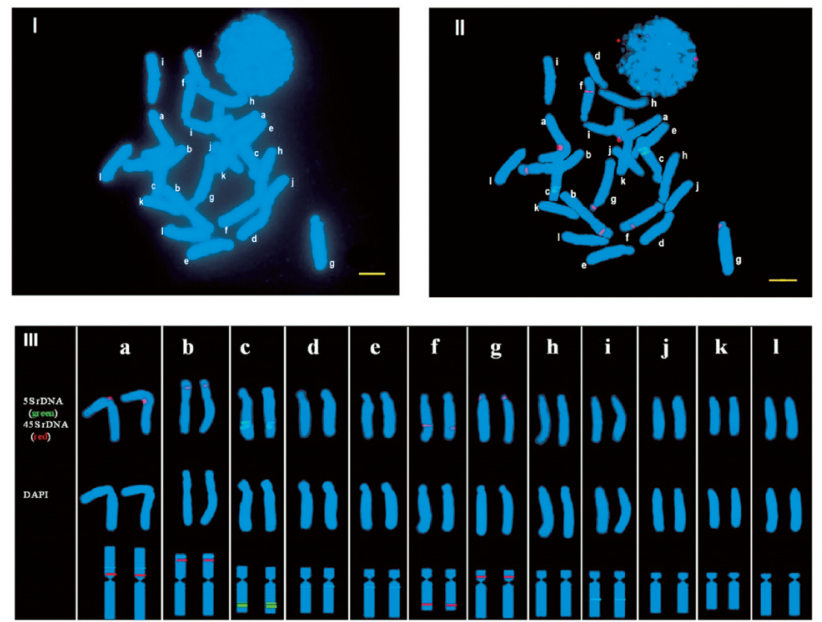

Fig. 2. Fluorescence in situ hybridization of mitotic metaphase chromosomes in diploid L. maximowiczii. (I): DAPI counter staining, (II): Green fluorescence indicates 5S rDNA loci and red fluorescence indicates 45S rDNA loci, (III): Karyotype. The bar represents a length of $10 \mu \mathrm{m}$.

g is a telocentric chromosome that contains a $45 \mathrm{~S}$ rRNA locus at a major secondary constriction in the short arm.

Chromosome $\mathbf{f}$ is a telocentric chromosome that possesses a $45 \mathrm{~S}$ rRNA locus near the telomere of the long arm, where the secondary constriction is scarcely visible by conventional chromosome staining. Chromosome $\mathbf{i}$ is a telocentric chromosome and includes a strong DAPI band in the middle of the long arm. Chromosome $\mathbf{h}$ is a telocentric chromosome with a similar chromosome shape to chromosome $\mathbf{j}$ but is distinguished by its smaller arm ratio. Chromosome $\mathbf{k}$ is telocentric and the shortest chromosome. Chromosome $\mathbf{l}$ is a telocentric chromosome but nearly resembles an acrocentric chromosome due to the very short length of the short arm.
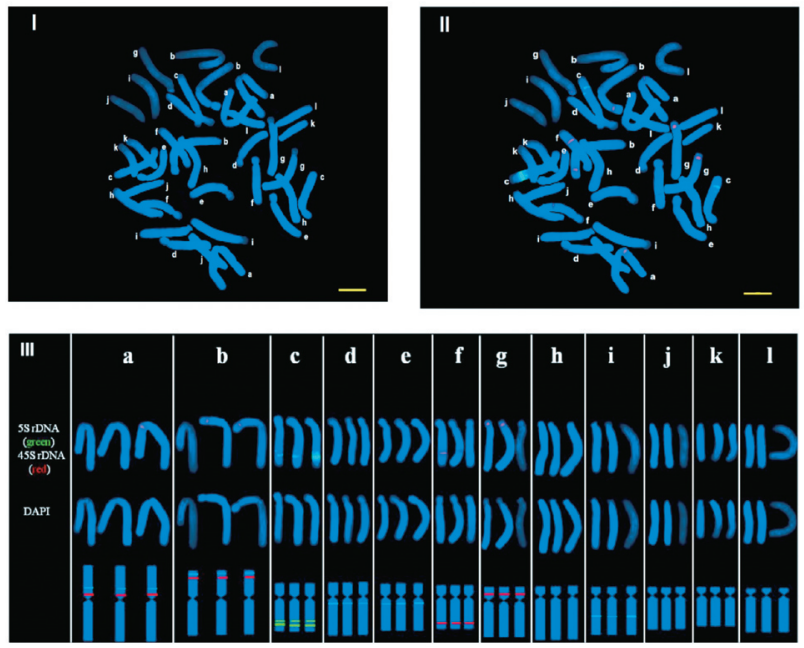

Fig. 3. Fluorescence in situ hybridization of mitotic metaphase chromosomes in triploid L. maximowiczii. (I) DAPI counter staining, (II); Green fluorescence indicates 5S rDNA loci and red fluorescence indicates 45S rDNA loci, (III): Karyotype. The bar represents a length of $10 \mu \mathrm{m}$.

\section{DISCUSSION}

Species in the genus Lilium are distributed across temperate regions of Eurasia and North America (Asano 1986). The basic chromosome number is 12 in the Lilium species, and most of the Lilium species are diploid ( $2 n=2 x=24)$ except for the triploids of $L$. lancifolium (Noda, 1978; Kim et al., 2006) and L. maximowiczii (Kim et al., 2015). L. maximowiczii is an endemic lily in Korea. It is found in inland of the Korean Peninsula. Until the recent report of triploids by our group (Kim et al., 2015), L. maximowiczii has been known as diploids in nature (Morinaga \& Fukushima, 1931; Kumazawa and Kimura, 1947; Kurita, 1948; Stewart, 1947; Noda, 1956, 
1966, and 1974; Ogihara, 1960; Son, 1982; Song and Seo, 1988; Sultana et al., 1010). The triploid plants were found in the alpine regions of Gangwon-do and Chungcheongbuk-do Provinces, which are located in the middle of the main Korean mountain range, so-called "Baekdudaegan", that stretches across most of the length of the Korean Peninsula (Kim et al., 2015). The triploid plants were robust and not inferior to the diploids in any of the environments we observed (Kim et al., 2015). Noda (1974) also observed the same phenomenon in artificial triploids. Willson (1925) described two distinguishable types of plants, a weak plant about 2 feet tall and a robust plant above 6 feet tall, in Hamkyungnam-do, North Korea. This distinction may be due to the difference in ploidy levels.

Although the plant morphology of $L$. maximowiczii, including its flowers, is highly similar to that of $L$. lancifolium, they show different characteristics from each other: stoloniferous underground stem in L. maximowiczii and bulbil attachment in L. lancifolium. Recently, Lee et al. (2015) confirmed that L. tigrinum is phylogenetically very distant from other Sinomartagon species including L. maximowiczii. The diploid populations of L. lancifolium, which are distributed narrowly in the western and southern coastal areas, as well as islands of the Korean peninsula (Kim et al., 2005 and 2006), never overlap with L. maximowiczii populations. Thus, it presently appears unlikely that triploid L. maximowic$z i i$ arise from the combination of diploid L. maximowiczii and diploid L. lancifolium.

The current study shows that there is only one cytotype in both diploid and triploid L. maximowiczii plants, indicating that the triploids are autotriploids. Production of polyploids from unreduced gametes has been found in other lily varieties by interspecific hybridization (BarbaGonzalez, 2004; Barba-Gonzalez, 2005; Chung et al., 2013; Fernandez et al., 1998). However, the triploid form of $L$. maximowiczii appeared to have originated by fertilization between a functional unreduced gamete (2n) and a normal reduced gamete (n) within a diploid population of $L$. maximowiczii. Autotriploid plants have often been observed in diploid populations of Lilium in nature (Samejima, 1958; Noda and Schmitzer, 1990).

Diploid L. maximowiczii populations are widely distributed throughout the main islands of the Japanese archipelago (Noda, 1956; Song and Seo, 1988; Asano, 1986), but L. maximowiczii populations in Korea are mainly triploid and show very limited distribution from the central inland area to the northern area where elevations are from $200 \mathrm{~m}$ to $1,400 \mathrm{~m}$. According to the distribution map of L. maximowiczii (Asano, 1986), L. maximowiczii populations in Korea are located at marginal areas of the distribution map. The big populations (population No. 28, 29 and 30) at the Mt. Sobaek are composed of both diploids and triploids, and cover more than $1 \mathrm{Km}$ in diameter around the mountain slopes at mid to high elevations $(700 \mathrm{~m} 1,400 \mathrm{~m})$. These populations in Mt. Sobaek are sympatric with $L$. cermum, L. distichum, and L. tsingtauense within a $4 \mathrm{Km}$ diameter region. These habitations of many sympatric species make it hard to deny allotriploid production in these species, since flowering times of these species overlap partially. Authors have never witnessed these habitats sympatric with many species in China and Japan except for $L$. tigrinum that is mainly dispersed via human activity. We found only autotriploids of $L$. maximowiczii populations in Korea and we did not find any L. tigrinum at Mt. Sobaek. The main Korean mountain range, so-called "Baekdudaegan", is recognized as a major refugia area for L. cernum, L. tsingtauense, L. amabile and L. distichum (Chung et al., 2014a; Chung et al., 2014b; Chung and Chung, 2014) during the last glacial period. Korean habitats of $L$. maximowiczii might have emerged from the same area as the refugia during the last glacial period. These high land area habitats of Korea show severe temperature fluctuation during the flower bud development (June: Max. $35^{\circ} \mathrm{C}-$ Min. $5^{\circ} \mathrm{C}$, during the last 50 years) (KMA, 2015). Considering $2 n$ gamete production can be stimulated by both low and high temperatures in many species (Ramsey and Schemske, 1990; Pecrix et al., 2011; Yamada et al., 2005) and in Lilium (van Tuyl and Stekelenburg, 1989), this extremely low or high temperature of Mt. Sobaek might have affected $2 n$ gamete production in L. maximowiczii, consequently producing polyploids. This hypothesis requires a systematic investigation of triploid formation in L. maximowiczii before conclusion can be drawn. Unfortunately, we are unable to discuss Japanese L. maximowiczii, because highland populations in Japan are unexplored as yet (Asano, 1986; Kurita, 1948; Noda, 1956; Noda, 1977).

Although it is well known about general trends for B-chromosome detection in many plants, their mode of origin remains unclear (Jones and Houben, 2003; Jones et al., 2008). Lilium species have been known to carry large genomes (Leitch et al., 2007). Besides establishing the occurrence of B-chromosomes in several species (Kayano, 1957), preferential transmission and maintenance in embryo-sac mother cells and Mendelian transmission in pollens have been investigated in L. callosum (Kayano, 1957; Kimura and Kayano, 1961). An origin of new aberrant small chromosomes was analyzed using hybrid lilies recently (Xie et al., 2014). Noda (2003) also reported about B-chromosome in Tiger lily.

Noda (1977) reported the karyotypes of the A and B cytotypes of the Japanese L. maximowiczii collections. While the arm index and general chromosome morphology were similar between the two cytotypes, chromosomes in the A cytotypes were larger than those of the B cytotypes. Noda (1977) and Song and Seo (1988) also reported the presence of different numbers of B-chromosomes in the Japanese accessions. Sultana et al. (2010) also noted two cytotypes in Korean L. maximowiczii by FISH analysis of $45 \mathrm{~S}$ rRNA loci. However, the origin of the L. maximowiczii in their study is uncertain. We analyzed 2 to 10 plants from each of 30 populations of diploids and triploids that were collected from diverse sites in Gangwon-do and Chungcheongbuk-do Provinces of Korea. However, we could not assign A or B cytotypes unequivocally in our samples, so we posit a single cytotype in Korean accessions of L. maximowic- 
zii. Moreover, none of the Korean collections carried B-chromosomes. B-chromosomes are dispensable elements; their inheritance is non-Mendelian and irregular (Jones and Houben, 2003). In maize, sequences of B-chromosomes were derived from different A-chromosomes (Cheng and Lin 2003). The B-chromosomes in the Japanese L. maximowiczii accessions must have derived from A-chromosomes. B-chromosome has never been found in Korea not only in a diploid form (Kim et al., 2005; Kim et al., 2006) but also in triploid forms (unpublished data) of Tiger lily. It is interesting that Japanese accessions of L. maximowiczii and L. lancifolium have numerous B-chromosomes, but Korean accessions do not. This apparent disparity may require further analysis.

With the combination of chromosome landmarks and FISH using rRNA loci, 9 of the 12 chromosomes of $L$. maximowiczii were easily identifiable. It was difficult to distinguish between chromosomes $\mathbf{h}, \mathbf{j}$, and $\mathbf{l}$ unequivocally. The three chromosomes $\mathbf{a}, \mathbf{b}$, and $\mathbf{g}$, showing secondary constrictions, were also observed previously by conventional staining (Noda, 1977). These two major secondary constriction sites could be the major nucleolus organizing regions (NORs), where the 45S RNA genes reside in $L$. maximowiczii. In addition to these two loci, we detected one more $45 \mathrm{~S}$ rRNA locus on chromosome f, where the secondary constriction was not detected. The FISH signal on chromosome $\mathbf{f}$ was weaker than that of the three major NOR loci on chromosomes $\mathbf{a}, \mathbf{b}$, and $\mathbf{g}$. Thus, the NOR loci on chromosomes $\mathbf{a}, \mathbf{b}$, and $\mathbf{g}$ would be the major nucleolar loci, and the locus on chromosome $\mathbf{f}$ would be the transcriptionally silent minor locus (Pikaard, 1999). Sultana et al. (2010) reported the karyotypes of 12 accessions in 9 Lilium species by FISH analysis of $45 \mathrm{~S}$ rRNA and $5 \mathrm{~S}$ rRNA loci. They arranged chromosomes according to their sizes from largest to smallest and reported that five chromosomes (chromosomes $1,2,6,7$, and 11) carry $45 \mathrm{~S}$ rRNA genes in $L$. maximowiczii. By chromosome shape, we could assign the identities $\mathbf{a}, \mathbf{b}, \mathbf{g}, \mathbf{f}$, and $\mathbf{k}$ to these five chromosomes (chromosomes 1, 2, 6, 7, and 11, respectively). The NOR loci on chromosomes $\mathbf{a}, \mathbf{b}$, and $\mathbf{g}$ in our study were also observed in their study. The $45 \mathrm{~S}$ rRNA loci on chromosomes $\mathbf{a}$ and $\mathbf{b}$ were highly conserved across Lilium species (Sultana et al., 2010). However, chromosome 6 showed only one hybridization signal in their study, whereas both hybridization signals were observed on chromosome $\mathbf{f}$ in our analysis. We also failed to detect additional 45S rRNA hybridization signals in our study. These discrepancies may be explained by the different sources of plant materials. The L. maximowiczii accessions were the collections from the alpine regions in Gangwon-do and Chungcheongbook-do Provinces, Korea, whereas the accessions of Sultana et al. (2010) were obtained from the Lily Experimental Station, Taean, Chungcheongnam-do Province, Korea. No further geographical information on the origin of this accession was available. The number of chromosomes carrying $45 \mathrm{~S}$ rRNA genes range from two in $L$. henryi to six in $L$. duchartrei (Marasek et al., 2004; Wang et al., 2012), and the loci in chromosomes $\mathbf{a}$ and $\mathbf{b}$ are highly conserved in most of the Lilium species studied (Sultana et al., 2010). The 5S rRNA locus on chromosome $\mathbf{c}$ is conserved in all of the Lilium species that were studied by Sultana et al. (2010). However, duplicated loci were only observed in the Sinomartagon section, such as L. maximowiczii, L. tigrinum, and L. amabile, but not in other Lilium species. Thus, the 5S rRNA duplication must have occurred only after the divergence of Sinomartagon section lilies.

In conclusion, we are reporting the karyotypes of diploid and triploid forms of $L$. maximowiczii using chromosomal landmarks such as chromosome length, arm ratio, secondary constrictions, DAPI bands, and FISH signals using 45S rRNA and 5S rRNA genes. Only one cytotype was observed in the karyotype analysis of both diploid and triploid populations, and the karyotypes of the diploid and triploid forms were identical, indicating that the triploid form emerged by autotriploidy.

\section{ACKNOWLEDGEMENTS}

This study was carried out with the support of the GSP Project No. 213003-04-2-SBN10, the Ministry of Agriculture, Food and Rural Affairs, Republic of Korea, and the Germplasm Reservation Center Program, Rural Development Administration, Republic of Korea (project PJ010372).

\section{REFERENCES}

Asano, Y. 1986 A numerical taxanomic study of the genus Lilium in Japan. J. Fac. Agric., Hokkaido Univ., 62: 333-341

Barba-Gonzalez, R., A. C. Lokker, K, B. Lim, M. S. Ramanna, and J. M. Van Tuyl 2004 Use of $2 n$ gametes for the production of sexual polyploids from sterile Oriental x Asiatic hybrids of lilies (Lilium). Theor. Appl. Genet., 109: 1125-1132

Barba-Gonzalez, R., K. B. Lim, M. S. Ramanna, R. F. G. Visser, and J. M. Van Tuyl 2005 Occurrence of 2 n gametes in the F-1 hybrids of Oriental x Asiatic lilies (Lilium): Relevance to intergenomic recombination and backcrossing. Euphytica, 143: $67-73$

Baranova, M. V. 1969 The geographical distribution of Lilium species in the flora of the USSR. Lily Yearbook, The Royal Horticultural Society, 32: 37-55

Cheng, Y. M. and B. Y. Lin 2003 Cloning and characterization of maize $B$ chromosome sequences derived from microdissection. Genetics, 159: 291-302

Chung, M. Y. and M. G. Chung 2014 Large effective population sizes and high levels of gene flow between subpopulations of Lilium cernum (Liliaceae). Biochem. Sys. Ecol., 54: 354361

Chung, M. Y., J. Lopez-Pujol, and M. G. Chung 2014a Comparative biogeography of the congener lilies Lilium distichum and Lilium tsingtauense in Korea. Flora, 209: 435-445

Chung, M. Y., M. G. Chung, J. Lopez-Pujol, M. X. Ren, Z. Y. Zhang, and S. J. Park 2014b Where the main mountain ranges in the Korean Peninsular a glacial refugium for plants? Insights from the congeneric pair Lilium cernuum - Lilium amabile. Biochem. Sys. Ecol., 53: 36-45

Chung, M. Y, J. D. Chung, M. Ramanna, J. M. van Tuyl, and K. B. Lim 2013 Production of polyploids and unreduced gametes in Lilium auratum $\mathrm{x}$ L. henryi hybrids. Int. J. Biol. Sci., 9: 693-701

Fernandez, A. M., T. Nakazaki, and T. Tanisaka 1998 Production of 
diploid and triploid interspecific hybrid between Lilium concolor and L. longiflorum by in vitro ovary slice culture. Plant Breeding, 117: 479-484

Heslop-Harrison, J. S., T. Schwarzacher, K. Anamthawat-Jonsson, A. R. Leich, M. Shi, and I. J. Leich 1991 In situ hybridization with automated chromosome denaturation. Technique, 3: 109-115

Hwang, Y. J., H. H. Kim, and K. B. Lim 2011 Karyotype analysis of Lilium tigrinum by FISH. Hort. Environ. Biotechnol., 52: 292-297

Jeong, J. H. 1991 Distribution and analysis of interspecific relationships in Korean native lilies. Ph. D. Thesis. Seoul National University, Korea (in Korean with English summery)

Jones, R. N. and A. Houben 2003 B chromosomes in plants: escapees from the A chromosome genome? Trends Plant Sci., 8: $417-423$

Jones, R. N., W. Viegas, and A. Houben 2008 A century of B chromosomes in plants: so What? Ann. Bot., 101: 767-775

Karafiátová, M., J. Bartos, D. Kopecký, L. Ma, K. Sato, A. Houben, N. Stein, and J. Dolez'el 2013 Mapping nonrecombining region in barley using multicolor FISH. Chromosome Res., 21: 739751

Kayano, H. 1957 Cytogenetic studies in Lilium callosum. Proc. Japanese Acad., 33: 553-558

KBIS 2013 Korea Biodiversity Information System. (http://www. nature.go.kr)

Kim, Y. 1996 Lily industry and research, and native Lilium species in Korea. Acta Hort., 414: 69-80

Kim, J. H., Xuan Y., M. Hiramatsu, and H. Okubo 2005 Natural habitats and ploid distribution of Lilium lancifolium in islands of the Bay of Kyunggi, Korea. J. Fac. Agr., Kyushu Univ., 50: $593-600$

Kim, J. H., Y. S. Kyung, Y. S. Choi, J. K. Lee, M. Hiramatsu, and H. Okubo 2006 Geographic distribution and habitat differentiation in diploid and triploid Lilium lancifolium of South Korea. J. Fac. Agr., Kyushu Univ., 51: 239-243

Kim, J. H., N. X. Truong, Y. S. Song, and N. S. Kim 2015 Natural triploid Lilium leichtlinii var. maximowiczii populations in Korea. Plant Species Biology, in press

Kimura, M. and H. Kayano 1961 The maintenance of supernumerary chromosomes in wild populations of Lilium callosum by preferential segregation. Genetics, 46: 1699-1712

KMA (Korea Meteorological Administration) 2015 http://www.kma. go.kr/: weather/climate/past_cal.jsp

Kumazawa, M. and M. Kimura 1947 Karyotypes in the Martagongroup. Chromosome morphology in Lilium III. Japan. J. Genet. Suppl., 1: 100-109

Kurita, M. 1948 Karyotype of Lilium maximowiczii Regel. Bot. Mag., Tokyo, 61: 83

Lee, S., J. H. Kim, K. C. Park, and N. S. Kim 2015 LTRretrotransposons and inter-retrotransposon amplified polymorphism (IRAP) analysis in Lilium species. Genetica, DOI 10.1007/s10709-015-9833-6

Leitch I. J., J M. Beaulieu, K. Cheung, L. Hanson, M. A. Lysak, M. F. Fay 2007 Punctuated genome size evolution in Liliaceae. $J$. Evol. Biol., 20: 2296-2308

Levan, A., K. Fredga, and A. A. Sunderge 1964 Nomenclature for centromeric position on chromosomes. Hereditas, 52: 201-220

Lighty, R. W. 1968 The lilies of Korea. Lily yearbook, The Royal Horticultural society, 31: 31-39

Lim, K. B., J. Wennekes, J. H. De Jong, E. Jacobsen, and J. M. Van Tuyl 2001 Karyotype analysis of Lilium longiflorum and Lilium rubellum by chromosome banding and fluorescence in situ hybridization. Genome, 44: 911-918

Marasek A., R. Hasterok, K. Wiehacha, and T. Orlikowska 2004 Determination by GISH and FISH of hybrid status in Lilium. Hereditas, 140: 1-7

Morinaga, T. and E. Fukushima 1931 Chromosome numbers of cultivated plants III. Bot. Mag., Tokyo, 45: 140-145

Noda, S. 1956 A cytological survey of natural populations of Lilium maximowiczii and L. tigrinum. Memo. Fac. Sci., Kyushu Univ., Ser. E (Biol.), 2: 95-100
Noda, S. 1966 Cytogenetics of the origin of triploid Lilium tigrinum. Bull. Osaka Gakuin Univ., 6: 85-140 (in Japanese with English summary)

Noda, S. 1974 Cytogenetic relationships between Lilium tigrinum and related species, and hybrid origin of Lilium tigrinum. Lily Yearbook, North Amer. Lily Soc., 27: 98-111

Noda, S. 1977 Leichtlin Lily as the variety of Maximowicz's Lily Lily Yearbook, North Amer. Lily Soc., 30: 127-133

Noda, S. 1978 Chromosomes of diploid and triploid forms found in the natural populations of tiger lily in Tsushima. Bot. Mag. Tokyo, 91: 279-283

Noda, S. 1986 Cytogenetic behavior, chromosomal differentiations, and geographic distribution in Lilium lancifolium (Liliaceae) Plant Species Biol., 1: 69-78

Noda, S., and E. Schmitzer 1990 Natural occurrence of triploid Lilium bulbiferum native to Europe. Lily yearbook, The North American Lily Society, 43: 78-81

Ogihara, R. 1960 On the supernumerary chromosomes found in the natural populations of Lilium auratum Lindle. and $L$. maximowiczii Regel. La Kromosomo, 44-55: 1500-1505

Pecrix Y., G. Rallo, H. Folzer, M. Cigna, S. Gudin, and M. Bris 2011 Polyploidization mechanism: temperature environment can induce diploid gamete formation in Rosa sp. J. Exp. Bot., 62 3587-3597

Pikaard, C. S. 1999 Nuclear dominance and silencing of transcription. Trends Plant Sci., 4: 478-483

Ramsey J., and D. W. Schemske 1998 Pathways, mechanism, and rates of polyploid formation in flowering plants. Annu. Rev. Ecol. Syst., 29: 467-501

Reeves, A., and J. Tear 2000 Micro Measure for Windows, version 3.3. Free program distributed by the authors over the Internet from http://www.colostate.eud/Depts/Biology/MicroMeasure

Samejima, J. 1958 Meiotic behavior of accessory chromosomes and their distribution in natural population of Lilium medeoloides A. Gray. Cytologia, 23: 159-171

Shimizu, M. 1969 Lilies in Japan. Lily Year Book, Roy. Hort. Soc., 32: 20-27

Son, J. H. 1982 C-banded karyotype analysis of Lilium in Korea. $\mathrm{Ph}$. D. Thesis. Busan National University, Korea (in Korean with English summery)

Song, N. H. 1987 Analysis of C-banded karyotypes and chromosomal relationships of Lilium species. Ph. D. thesis, Kyungpook Natl. Univ. Daegu, Korea

Song N. H. and B. S. Seo 1988 Cytogenetic study of Lilium maximowiczii Regel using differential Giemsa Stain. Research Review of Kyungpook National Univ., 45: 63-68

Stewart, R. N. 1947 The morphology of somatic chromosomes in Lilium. Am. J. Bot., 34: 9-26

Sultana, S., S. H. Lee, J. W. Bang, and H. W. Choi 2010 Physical mapping of rRNA gen loci and inter-specific relationships in wild Lilium distributed in Korea. J. Plant Biol., 53: 433-443

van Tuyl, J. M., and P. Stekelenburg 1989 Geneotypic and environmental variation in production of 2 n-gamete in Lilium. In "Sexual reproduction of higher plant", ed. by P. Gori and E. Pacini, Springer Verlag, Berlin, p. 486

Wang, X., S. Xie, Y. Zhang, and L. Niu 2012 Chromosome analysis and mapping of ribosomal genes by fluorescent in situ hybridization (FISH) in four endemic lily species (Lilium) in Qinling mountain, China. Pak. J. Bot., 44: 1319-1323

Willson, E. H. 1925 The lilies of Eastern Asia. Dulau \& Co. Ltd. London

Xie, S., A. Marasek-Ciolakowska, M. S. Ramanna, P. Arens, R. G. F. Visser, and J. M. van Tuyl 2014 Characterization of B chromosomes in Lilium hybrids through GISH and FISH. Plant Syst. Evol., 300: 1771-1777

Yamada, A., R. Tao, and A. Sugiura 2005 Influence of low temperature before flowering on the occurrence of unreduced pollen in Japanese persimmon (Diospyros kaki Thunb.) HortScience, 40: 24-28

Zhang, P., R. Kynast, and B. Friebe 2014 Multicolor fluorescence in situ hybridization. http://www.ksu.edu/wgrc 